\title{
Effect of Copper Pretreatment on Growth of Graphene Films by Chemical Vapor Deposition
}

\author{
SUN Futong ${ }^{1,2}$, FENG Aihu ${ }^{2}$, CHEN Bingbing ${ }^{2}$, YU Yun ${ }^{2}$, YANG Hong $^{1}$
}

(1. College of Chemistry and Materials Science, Shanghai Normal University, Shanghai 200234; 2. Key Laboratory of Inorganic Coating Materials of Chinese Academy of Sciences, Shanghai Institute of Ceramics, Chinese Academy of Sciences, Shanghai 201899, China)

\begin{abstract}
Chemical vapor deposition (CVD) is an effective method for preparing large-size and high-quality graphene materials. The properties of the metal catalysts are direcly related to the quality of the prepared graphene films, so the surface pretreatment of the metal catalysts is required. In this study, the effects of different pretreatment methods on copper substrates are investigated, and the combination of passivation paste pickling and electrochemical polishing is proposed to be an effective method to modify the surface morphology of copper catalyst. The electrochemical polishing parameters (such as voltage, time) and the copper substrate annealing parameters (such as annealing temperature, time) are systematically studied. This study demonstrates that high electrochemical polishing voltage and long polishing time easily lead to the excessive polishing. It is appropriate to set the polishing voltage and polishing time to $8 \mathrm{~V}$ and $8 \mathrm{~min}$, respectively. It is found that the annealing temperature and time have significant effects on the grain size of the copper catalyst. After annealing at $1000{ }^{\circ} \mathrm{C}$ for $30 \mathrm{~min}$, the grain is larger and more uniform. In addition, the structure characterization of graphene prepared by CVD is also performed. According to the SEM image and Raman spectrum, the few-layer, high-quality graphene film is successfully prepared.
\end{abstract}

Key words: copper substrate; pretreatment; chemical vapor deposition; graphene

In 2004, Geim and Novoselov ${ }^{[1]}$ successfully obtained the single-layer graphene material by mechanical exfoliation. It is first confirmed that the two-dimensional carbon material can exist alone. Graphene is an ideal two-dimensional material composed of a single-layer of carbon atoms, and its atoms form a six-carbon ring planar structure by $\mathrm{sp}^{2}$ hybridization ${ }^{[2]}$. Graphene is the basic unit of other carbon materials, and it can be wrapped up into fullerenes, rolled into carbon nanotubes or stacked into graphite. The thickness of a single-layer graphene is about $0.335 \mathrm{~nm}$, which gives it excellent optical properties, electrical properties and mechanical properties ${ }^{[3-5]}$. For example, the single-layer graphene only absorbs $2.3 \%$ of the visible light, and it looks almost transparent. The carrier mobility of single-layer graphene at room temperature is about $15000 \mathrm{~cm}^{2} /(\mathrm{V} \cdot \mathrm{s})$, which is 10 times higher than that of silicon. In addition, its Young's modulus is up to $1 \mathrm{Tpa}$, and the compressive strength reaches $180 \mathrm{GPa}$, which is 100 times of ordinary steel. At the same time, the unique two-dimensional structure endows the graphene with excellent thermal properties ${ }^{[6-8]}$. The thermal conductivity of graphene theoretically reaches $5300 \mathrm{~W} /(\mathrm{m} \cdot \mathrm{K})^{[9]}$, which is about 5 times of diamond, 10 times of copper, and 100 times of silicon. However, the excellent properties are closely related to the number of graphene layers. As the number of graphene layers increases, the performances of graphene, like absorption, carrier mobility, and Young's modulus, are greatly reduced. For instance, the thermal conductivity of the graphene with ten layers is reduced to below $1000 \mathrm{~W} /(\mathrm{m} \cdot \mathrm{K})^{[10]}$.

$\mathrm{Up}$ to now, there have been a variety of methods for preparing the graphene materials, mainly including the mechanical exfoliation ${ }^{[1]}$, redox method ${ }^{[11-12]}$, liquid phase exfoliation $^{[13-14]}$, epitaxial growth ${ }^{[15]}$, chemical vapor deposition (CVD) ${ }^{[16-18]}$ and so on. The mechanical exfoliation and liquid phase exfoliation methods have problems of low yield and high energy cost, while the size and morphology of graphene prepared by redox method

Received date: 2019-12-05; Revised date: 2020-01-26

Biography: SUN Futong (1992-), male, Master candidate. E-mail: sunfutong@student.sic.ac.cn 孙付通(1992-), 男, 硕士研究生. E-mail: sunfutong@student.sic.ac.cn

Corresponding author: YU Yun, professor. E-mail: yunyush@mail.sic.ac.cn; YANG Hong, professor. E-mail: yanghong@shnu.edu.cn 于 云, 研究员. E-mail: yunyush@mail.sic.ac.cn; 杨 红, 教授. E-mail: yanghong@shnu.edu.cn 
are difficult to control and the quality is not guaranteed. The process of epitaxial growth of graphene is cumbersome. Compared with the mentioned methods above, CVD is the most effective method for obtaining high quality, large-sized graphene, which has the advantages of low cost and high yield ${ }^{[19-20]}$. By controlling the decomposition and deposition of carbon atoms at high temperature and low pressure, the structure and number of layers of graphene on catalyst substrate surface can be effectively controlled. Since the catalyst substrate provide the sites for graphene nucleation and growth, the surface features of the catalyst substrate, such as roughness $^{[21]}$, defects ${ }^{[22-23]}$, grain size ${ }^{[24-25]}$ and crystal plane orientation $^{[26]}$ etc., directly affect the quality and size of the final graphene.

The substrate pretreatment can significantly reduce the catalyst surface defects and impurities ${ }^{[27-30]}$. In this work, the effects of different $\mathrm{Cu}$ substrate pretreatment methods on the quality of graphene were studied, and the common pickling, passivation pickling paste and electrochemical polishing were compared. A novel method for treating copper substrates by the combination of passivation paste pickling and electrochemical polishing is proposed. The effects of working voltage and time on the $\mathrm{Cu}$ substrate in electrochemical polishing process were discussed. Then the effect of annealing process on the grain of $\mathrm{Cu}$ substrate was systematically studied. In addition, the structure morphologies of produced graphene films were characterized.

\section{Experimental}

\subsection{Materials}

The isopropyl alcohol, anhydrous ethanol, concentrated sulfuric acid, phosphoric acid and hydrochloric acid were purchased from Sinopharm Chemical Reagent Co., Ltd. (China). The polyethylene glycol, and glycerol were purchased from Shanghai Titan Chemical Co., Ltd. (China). The tributyl phosphate was purchased from Aladdin reagent Co., Ltd. (China), and the copper foil (purity 99.9\%, thickness $100 \mu \mathrm{m}$ ) was from Chinalco Luoyang Copper Industry Co., Ltd. (China).

\subsection{Pretreatment of copper substrates}

In this work, different methods are used to pretreat copper substrate. The untreated copper foil was respectively washed in isopropyl alcohol, absolute ethanol, and deionized water via an ultrasonic for about $10 \mathrm{~min}$. Then, 1) Etching treatment with hydrochloric acid. The sonicated copper foil was placed in 10\% hydrochloric acid solution for $2 \mathrm{~min}$, then rinsed with deionized water, and blown dry with nitrogen. 2) Hydrochloric acid etching and electrochemical polishing. Some copper foils etched by hydrochloric acid were furtherly electrochemically polished. The electropolishing time was set to $8 \mathrm{~min}$ and voltage to $8 \mathrm{~V}$. The polishing liquid consisted of $100 \mathrm{~g}$ of phosphoric acid, $30 \mathrm{~g}$ of sulfuric acid, $5 \mathrm{~g}$ of hydrochloric acid, $8 \mathrm{~g}$ of polyethylene glycol, $5 \mathrm{~g}$ of glycerin, $25 \mathrm{~g}$ of deionized water, and $1 \mathrm{~g}$ of tributyl phosphate. 3) Etching treatment with passivation paste. The surface of copper foil was carefully scrubbed with the passivation paste, and the scrubbing time was set to 2 min. 4) Passivation paste etching and electrochemical polishing. A portion of copper foils treated with the passivation paste were subjected to electrochemical polishing treatment.

\subsection{Graphene growth by CVD}

The pretreated copper foil was placed in a horizontal quartz tube furnace (inner diameter of $100 \mathrm{~mm}$ ). The system was evacuated to about $1.33 \mathrm{~Pa}$, and then filled with $200 \mathrm{sccm}$ of argon to atmospheric pressure. Argon (Ar, 99.999\% purity) and 100 sccm hydrogen $\left(\mathrm{H}_{2}\right.$, 99.999\% purity) gas mixture was introduced for $10 \mathrm{~min}$, then the temperature program started. When the temperature and pressure reach the desired values, methane was introduced (from $0.5 \mathrm{sccm}$ to $5.0 \mathrm{sccm}$ ). The growth temperature was set to $1060{ }^{\circ} \mathrm{C}$, and the process was carried out for $25 \mathrm{~min}$. Then, it was cooled to room temperature under an atmosphere of argon and hydrogen.

\subsection{Characterization}

The surface morphology of copper substrates and graphene samples were examined by an optical microscope (OM, DM2500M, Leica Instruments Co., Ltd.) and a scanning electron microscope (SEM, Hitach S-4800, Bruker). The graphene structure was tested by Raman spectroscopy ( XploRA PLUS, HORIBA, Japan).

\section{Results and discussion}

\subsection{Different pretreatment on copper substrate}

The copper substrates were treated by different methods, and the optical microscope images of different samples are shown in Fig. 1. As can be seen from Fig. 1(a), there are a large number of streaks and impurity defects on the surface of the untreated copper foil. From Fig. 1(b), the surface morphology of the copper foil does not change much, and the surface still has streaks and defects after etching with hydrochloric acid for $20 \mathrm{~h}$. Therefore, the dilute hydrochloric acid etching treatment does not give the copper foil a smooth surface. When the copper foil is further processed by electrochemical polishing, the surface morphology of copper foil is changed significantly in Fig. 1(c). The original stripe disappears and the surface is more smooth. Fig. 1(d) is the photomicrograph of the copper foil treated with passivation paste. It can be 

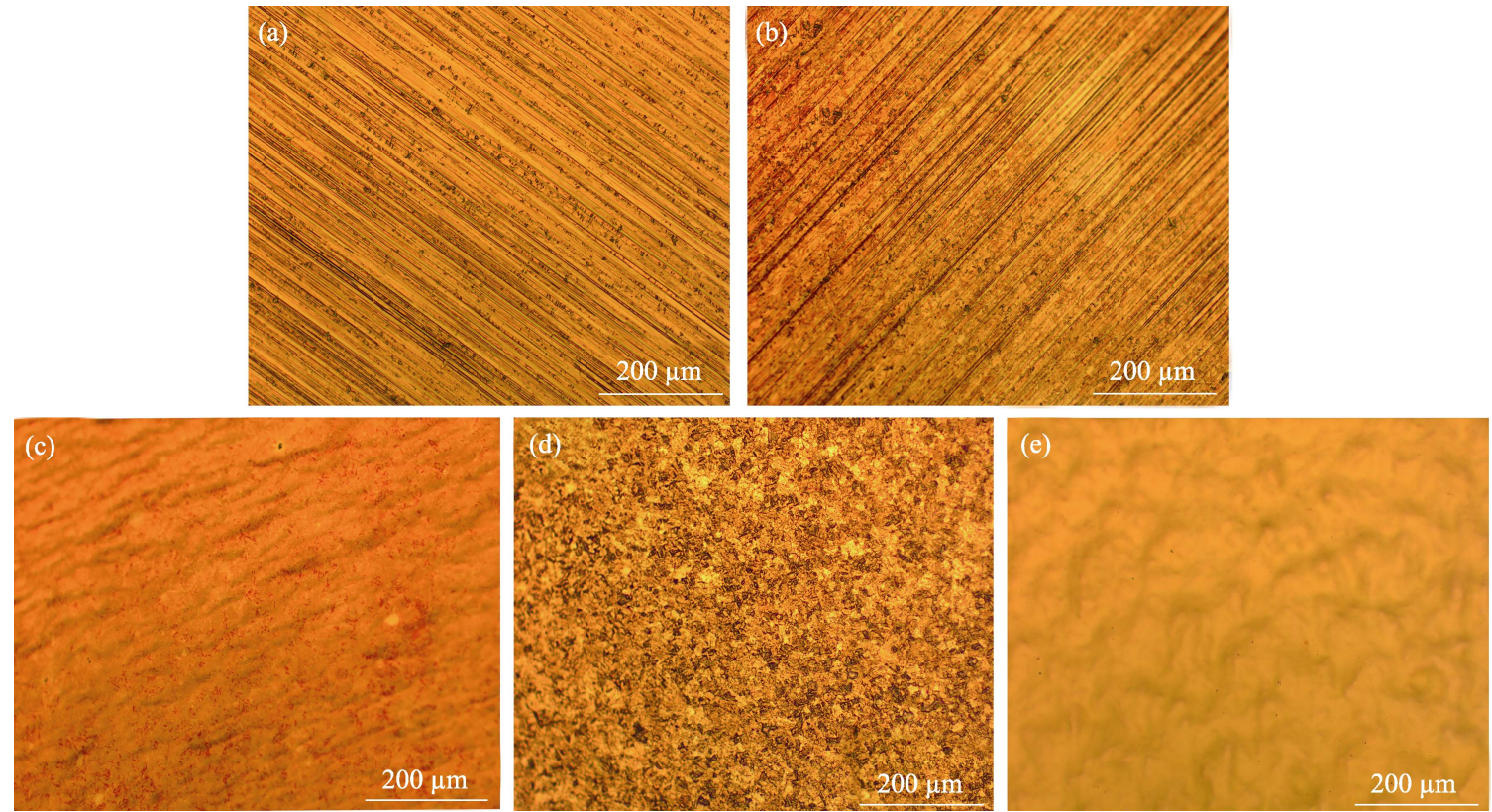

Fig. 1 OM images of different copper substrates

(a) Untreated copper substrate; (b) Hydrochloric acid etching treatment; (c) Hydrochloric acid etching and electrochemical polishing treatment; (d) Passivation paste etching; (e) Passivation paste etching and electrochemical polishing treatment

seen that the corrosion effect is obvious and the surface morphology is completely changed, but the surface exhibits loose and rough appearance. Then the copper foil treated by the passivation paste is furtherly subjected to electrochemical polishing treatment. Surprisingly, the flatness and smoothness of the copper foil substrate are significantly improved, and the mirror effect is macroscopically achieved as shown in Fig. 1(e). So the combination of the passivation paste pickling and electrochemical polishing is an effective method for treating copper substrates.

\subsection{Effect of electrochemical polishing volt- age and polishing time}

In order to explore the process parameters of electrochemical polishing, the effect of polishing voltage and polishing time were studied. As shown in Fig. 2, three polishing voltages, $1.2,4.0$ and $8.0 \mathrm{~V}$, were selected. It can be seen from Fig. 2(a1-a4) that when the polishing voltage is set to $1.2 \mathrm{~V}$, electrochemical polishing treatment has little effect on the copper foil. There are still some defects such as streaks and pits on the surface of copper foils even if the polishing time increases to $40 \mathrm{~min}$. When voltage is $4 \mathrm{~V}$, the surface of the copper foil treated for 10 min changes significantly in Fig. 2(b1), and the streaks become shallow. With the polishing time increasing to $30 \mathrm{~min}$, the streaks and defects on copper surface are completely removed as shown in Fig. 2(b3). However, the excessive corrosion pits appear if polishing time is up to 40 min. In Fig. 2(b4), it can be demonstrated that there are some corrosion pits on the surface of the copper foil. As the polishing voltage increasing to $8 \mathrm{~V}$, the polishing time also has great influence on copper surface morphology. When the polishing time is $8 \mathrm{~min}$, the surface of the copper foil substrate is flat and smooth as shown in Fig. 2(c1). The surface smoothness is improved significantly with the polishing time increasing, but excessive prolonging polishing time easily causes corrosion (Fig. 2(c2-c4)).

Therefore, the copper foil cannot be significantly polished when the polishing voltage is too low, while the excessive polishing time causes excessive polishing with high voltage. Based on the results, the appropriate polishing voltage and time are set as $8 \mathrm{~V}$ and $8 \mathrm{~min}$, respectively.

\subsection{Effect of annealing temperature}

In the growing process of graphene, the grain size and uniformity of copper catalyst have great influence on graphene quality and size. The temperature is a very important factor, and the annealing treatment can signifycantly improve the surface morphology of the copper foil substrate. The copper foils were annealed at different temperatures for $30 \mathrm{~min}$. It can be seen from Fig. 3(a) that when the annealing is performed at $800{ }^{\circ} \mathrm{C}$ for $30 \mathrm{~min}$, the grain is less than $100 \mu \mathrm{m}$ in size and ununiform. As the annealing temperature rises to $900{ }^{\circ} \mathrm{C}$, the surface morphology of the copper foil substrate is slightly changed, and some grain become larger $(\sim 200 \mu \mathrm{m})$. But the annealing effect is still poor, and grain size is still uneven. When the annealing temperature is increased to 1000 and $1060{ }^{\circ} \mathrm{C}$, the grain size of the copper foil is larger and the uniformity is significantly improved, as shown in Fig. 3(c, d). 

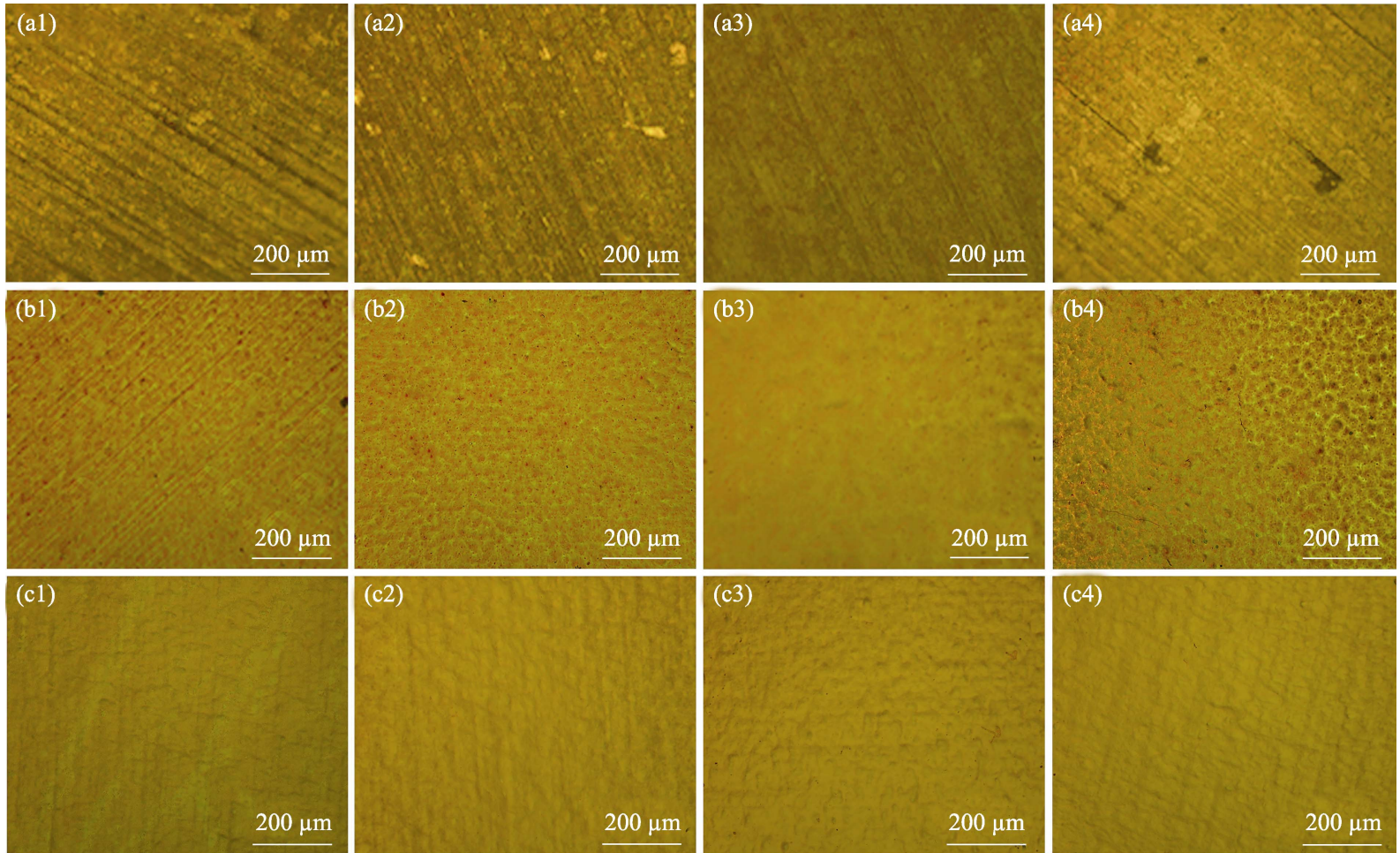

(c4)

Fig. 2 OM images of copper substrates electrochemical polished with different voltages and time (a1) $1.2 \mathrm{~V} / 10 \mathrm{~min}$; (a2) $1.2 \mathrm{~V} / 20 \mathrm{~min}$; (a3) $1.2 \mathrm{~V} / 30 \mathrm{~min}$; (a4) $1.2 \mathrm{~V} / 40 \mathrm{~min}$; (b1) $4 \mathrm{~V} / 10 \mathrm{~min}$; (b2) $4 \mathrm{~V} / 20 \mathrm{~min}$; (b3) $4 \mathrm{~V} / 30 \mathrm{~min}$; (b4) $4 \mathrm{~V} / 40 \mathrm{~min}$; (c1) $8 \mathrm{~V} / 6 \mathrm{~min}$; (c2) $8 \mathrm{~V} / 8 \mathrm{~min}$; (c3) $8 \mathrm{~V} / 10 \mathrm{~min}$; (c4) $8 \mathrm{~V} / 12 \mathrm{~min}$
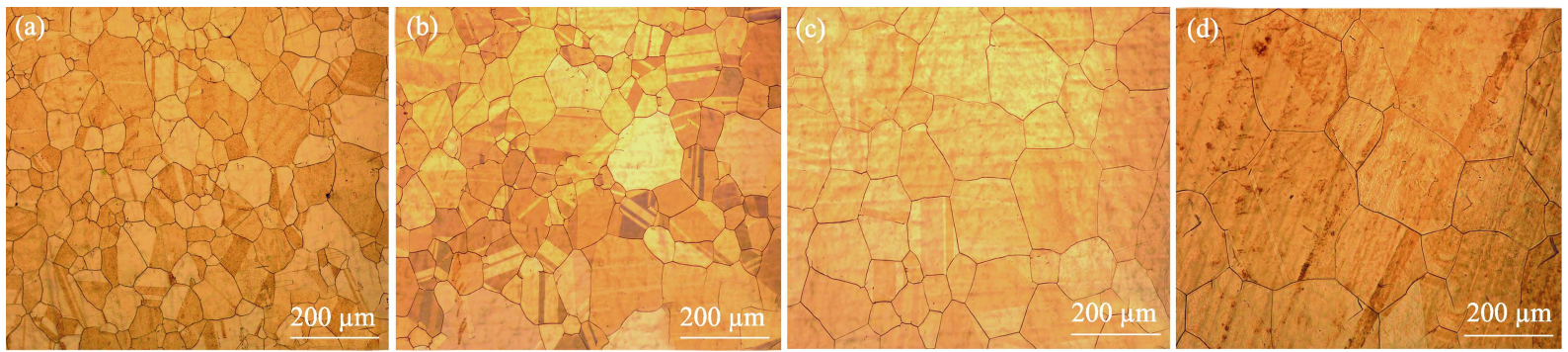

Fig. 3 OM images of copper substrates annealed at different temperatures for $30 \mathrm{~min}$ (a) $800{ }^{\circ} \mathrm{C}$; (b) $900{ }^{\circ} \mathrm{C}$; (c) $1000{ }^{\circ} \mathrm{C}$; (d) $1060{ }^{\circ} \mathrm{C}$

\subsection{Effect of annealing time}

In addition to annealing temperature, the annealing time also seriously affects copper grain size and its uniformity. When the annealing temperature is $1000{ }^{\circ} \mathrm{C}$ with no holding time, the grain is unevenly distributed with dimension less than $200 \mu \mathrm{m}$, as shown in Fig. 4(a). However, the grain becomes significantly larger as the annealing time is kept at $30 \mathrm{~min}$, and most of the grains exceed $200 \mu \mathrm{m}$ with improved uniformity (Fig. 4(b)). With the annealing time increasing to 90 or $120 \mathrm{~min}, \mathrm{Cu}$ grains continue to increase $(>400 \mu \mathrm{m})$, while the number of grains decreases (Fig. 4(c, d)). However, too long annealing time can increase energy cost. Considering the results from Fig. 3 and Fig. 4, the copper foil substrate with larger grain size and uniform distribution can be obtained by annealing at $1000{ }^{\circ} \mathrm{C}$ for $30 \mathrm{~min}$.

\subsection{Graphene characterization}

SEM image of graphene sample by CVD growth is shown in Fig. 5. Two regions, gray and dark gray area are clearly visible, indicating that different layers of graphene are grown. In order to analyze the quality of the prepared graphene, the graphene in different regions are characterized by the Raman spectra (Fig. 6). The D peak in Raman spectra represents the defect peak of graphene, while the $G$ peak represents the characteristic peak of carbon $\mathrm{sp}^{2}$, reflecting the crystallinity and symmetry. 2D is the second-order Raman scattering peak of the region boundary phonon, which is used to determine the existence of graphene. So the $I_{\mathrm{G}} / I_{\mathrm{D}}$ demonstrates the degree of defect of the graphene crystal, and $I_{2 \mathrm{D}} / I_{\mathrm{G}}$ represents graphene layer. Fig. 6(a) is the Raman spectrum of the quartz substrate. The quartz substrate can produce a light scattering effect to cause characteristic peaks other than graphene in Fig. 6(b, c). Compared with the Raman spectrum of the graphene sample in gray area, the $\mathrm{D}$ band intensity of graphene in dark gray area is lower, while the 


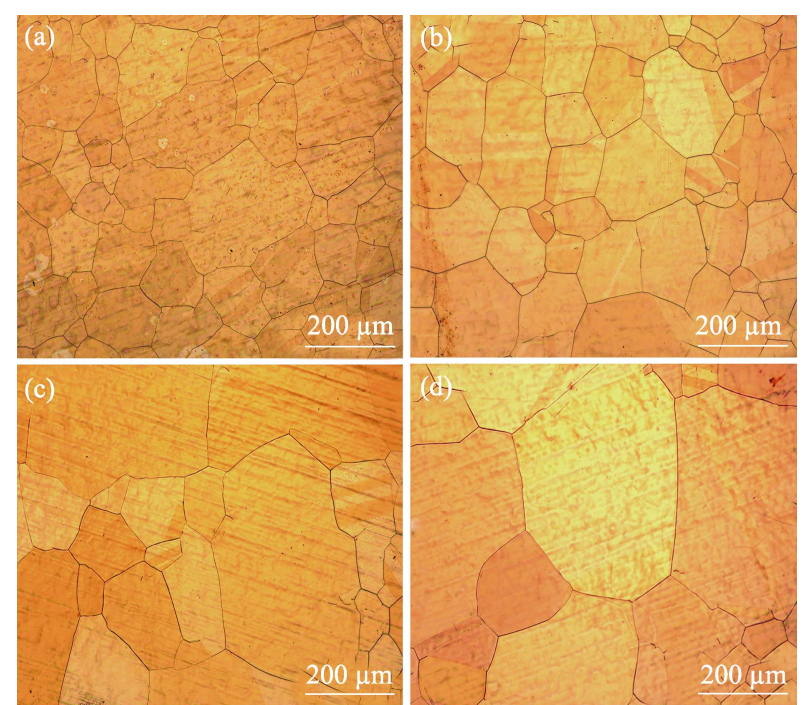

Fig. 4 OM images of copper substrates annealed at $1000{ }^{\circ} \mathrm{C}$ for different time

(a) 0; (b) $30 \mathrm{~min}$; (c) $90 \mathrm{~min}$; (d) $120 \mathrm{~min}$

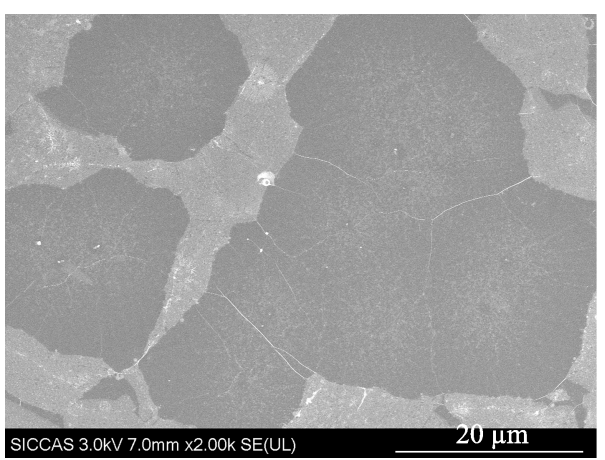

Fig. 5 SEM image of graphene sample

2D band intensity is significantly higher, as show in Fig. $6(\mathrm{~b}, \mathrm{c})$. In addition, the $I_{\mathrm{D}} / I_{\mathrm{G}}$ is slightly decreased, and the $I_{2 \mathrm{D}} / I_{\mathrm{G}}$ is obviously increased in Table 1 . Therefore, the graphene in dark gray area has fewer defects and better quality.

\section{Conclusion}

The effects of different pretreatment on the surface morphology of copper substrates were studied. It can be found that the combined treatment of passivation paste pickling and electrochemical polishing can effectively remove surface defects on copper substrates. The influence of polishing process and annealing process parameters on the copper substrate are systematically demonstrated, and a process for preparing high-quality graphene by CVD is developed. According to the SEM image and Raman spectrum, the graphene film prepared in this work is few-layer, large-size, high-quality. It is worth emphasizing that the copper foil used in this work is the common copper foil, and its purity is only $99.9 \%$. Overall, our work provides a novel method for large-scale preparation of high-quality graphene.
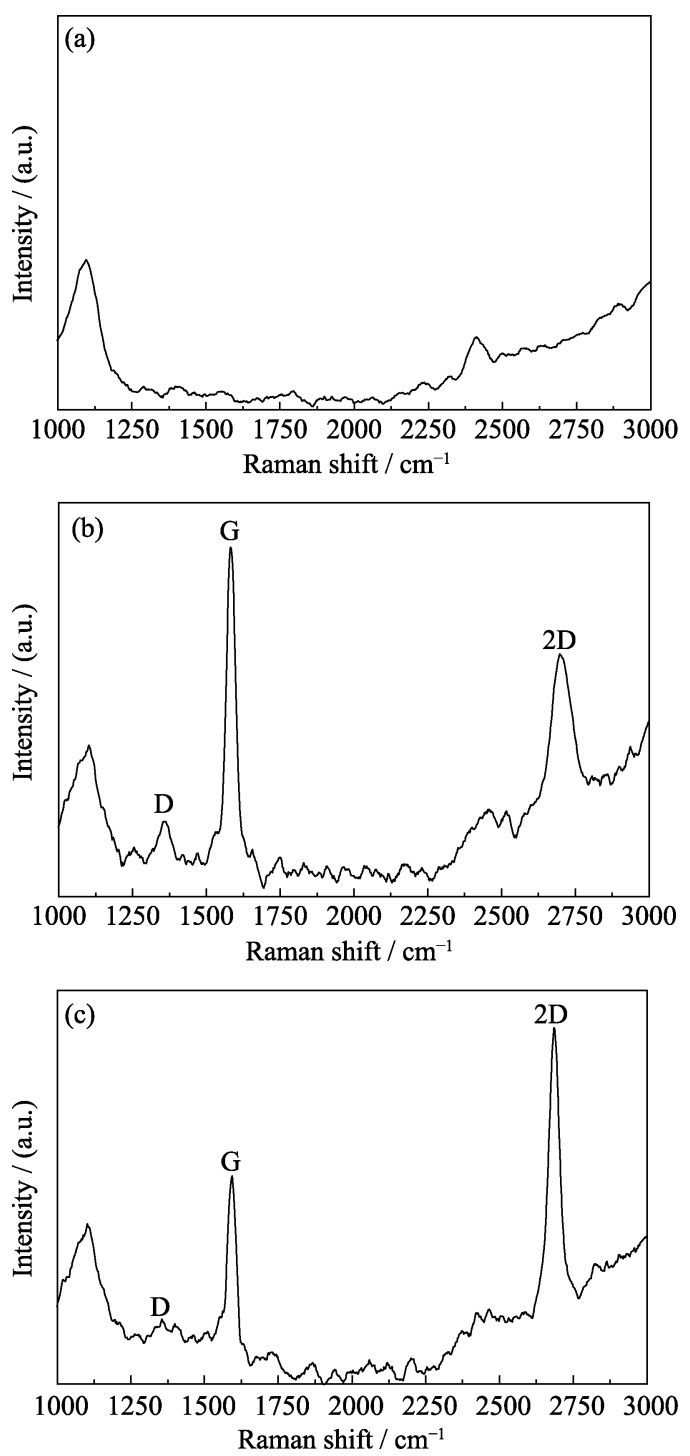

Fig. 6 Raman spectra of quartz substrate (a), graphene sample in gray area (b), and graphene sample in dark gray area (c)

Table 1 Comparison of the Raman characteristic peak in different graphene areas

\begin{tabular}{lccccc}
\hline \multicolumn{1}{c}{ Area } & $\begin{array}{c}\mathrm{D} \\
\text { band } / \mathrm{cm}^{-1}\end{array}$ & $\begin{array}{c}\mathrm{G} \\
\text { band } / \mathrm{cm}^{-1}\end{array}$ & $\begin{array}{c}2 \mathrm{D} \\
\text { band } / \mathrm{cm}^{-1}\end{array}$ & $I_{\mathrm{D}} / I_{\mathrm{G}}$ & $I_{2 \mathrm{D}} / I_{\mathrm{G}}$ \\
\hline Gray area & 1354 & 1581 & 2697 & 0.57 & 0.83 \\
Dark gray area & 1354 & 1592 & 2684 & 0.26 & 1.29 \\
\hline
\end{tabular}

\section{References:}

[1] NOVOSELOV K S, GEIM A K, MOROZOV S V, et al. Electric field effect in atomically thin carbon films. Science, 2004, 306(5696): 666-669.

[2] TAN L F, ZENG M Q, WU Q, et al. Direct growth of ultrafast transparent single-layer graphene defoggers. Small, 2015, 11(15): $1840-1846$.

[3] KAPLAS T, KARVONEN L, AHMADI S, et al. Optical characterization of directly deposited graphene on a dielectric substrate. Optics Express, 2016, 24(3): 2965-2970.

[4] LI X S, CAI W W, AN J H, et al. Large-area synthesis of high-quality and uniform graphene films on copper foils. Science, 2009, 324(5932): 1312-1314. 
[5] GALASHEV A E. Computer simulation of the thermal stability of nickel films on two-layer graphene. High Temperature, 2014, 52(5): 633-639.

[6] ZENG J, JI X X, MA Y H, et al. 3D graphene fibers grown by thermal chemical vapor deposition. Advanced Materials, 2018, 30(12): 1705380 .

[7] LIM G, KIHM K D, KIM H G, et al. Enhanced thermoelectric conversion efficiency of cvd graphene with reduced grain sizes. Nanomaterials, 2018, 8(7): 557.

[8] XIONG Z, WANG X Y, LEE K H K, et al. Thermal transport in supported graphene nanomesh. ACS Applied Materials \& Interfaces, 2018, 10(11): 9211-9215.

[9] BALANDIN A A, GHOSH S, BAO W, et al. Superior thermal conductivity of single-layer graphene. Nano Lett, 2008, 8(3): 902-907.

[10] REINA A, JIA X, HO J, et al. Large area, few-layer graphene films on arbitrary substrates by chemical vapor deposition. Nano Lett, 2008, 9(1): 30-35.

[11] ZHANG N, ZHAO X K, FU X B, et al. Preparation and characterization of polyamide-6/reduced graphene oxide composite microspheres. ChemistrySelect, 2019, 4(38): 11294-11301.

[12] MAHAMAI N, PROM-ANAN T, SARAKONSRI T. Preparation and characterization of platinum alloy catalysts supported on $n$-doped reduced graphene oxide for anode in direct ethanol fuel cell (DEFC). Materials Today-Proceedings, 2019, 17(4): 1561-1568.

[13] TIAN J, GUO L, YIN X L, et al. The liquid-phase preparation of graphene by shear exfoliation with graphite oxide as a dispersant. Materials Chemistry and Physics, 2019, 223: 1-8.

[14] ZHANG D D, FU L, LIAO L, et al. Preparation, characterization, and application of electrochemically functional graphene nanocomposites by one-step liquid-phase exfoliation of natural flake graphite with methylene blue. Nano Research, 2012, 5(12): 875-887.

[15] MA T, ARIGA H, TAKAKUSAGI S, et al. Smooth epitaxial copper film on sapphire surface suitable for high quality graphene growth. Thin Solid Films, 2018, 646: 12-16.

[16] MATTEVI C, KIM H, CHHOWALLA M. A review of chemical vapour deposition of graphene on copper. Journal of Materials Chemistry, 2011, 21(10): 3324-3334.

[17] FANG L P, YUAN W, WANG B, et al. Growth of graphene on $\mathrm{Cu}$ foils by microwave plasma chemical vapor deposition: the effect of in-situ hydrogen plasma post-treatment. Applied Surface Science, 2016, 383: 28-32.
[18] MENDOZA C D, CALDAS P G, FREIRE F L, et al. Growth of single-layer graphene on $\mathrm{Ge}(100)$ by chemical vapor deposition. Applied Surface Science, 2018, 447: 816-821.

[19] WANG H, WANG G Z, BAO P F, et al. Controllable synthesis of submillimeter single-crystal monolayer graphene domains on copper foils by suppressing nucleation. Journal of the American Chemical Society, 2012, 134(44): 18476-18476.

[20] ZHAO X, GOU L. Comparative analysis of graphene grown on copper and nickel sheet by microwave plasma chemical vapor deposition. Vacuum, 2018, 153: 48-52.

[21] GOLI P, NING H, LI X S, et al. Thermal properties of graphenecopper-graphene heterogeneous films. Nano Letters, 2014, 14(3): $1497-1503$.

[22] XU Z. Heat transport in low-dimensional materials: a review and perspective. Theoretical and Applied Mechanics Letters, 2016, 6(3): 113-121.

[23] YARIFARD M, DAVOODI J, RAFII-TABAR H. Computation of the thermal resistance in graphene sheets with a rectangular hole. Computational Materials Science, 2017, 126: 29-34.

[24] LEE W, KIHM K D, KIM H G, et al. In-plane thermal conductivity of polycrystalline chemical vapor deposition graphene with controlled grain sizes. Nano Letters, 2017, 17(4): 2361-2366.

[25] THIELE S, REINA A, HEALEY P, et al. Engineering polycrystalline $\mathrm{Ni}$ films to improve thickness uniformity of the chemicalvapor-deposition-grown graphene films. Nanotechnology, 2010, 21(1): 015601.

[26] HU Y, XIE X, SUN C, et al. Assembling reduced graphene oxide hydrogel with controlled porous structures using cationic and anionic surfactants. Nanotechnology, 2019, 30(50): 505602.

[27] KIM S M, HSU A, LEE Y H, et al. The effect of copper precleaning on graphene synthesis. Nanotechnology, 2013, 24(36): 365602.

[28] HU X D, ZHANG M, XUE Z Y, et al. The effect of copper pretreatment on graphene synthesis by ion implantation into $\mathrm{Ni} / \mathrm{Cu}$ substrate. Semiconductor Science and Technology, 2018, 33(7): 074001.

[29] JEONG H, HWANG W T, SONG Y, et al. Highly uniform monolayer graphene synthesis via a facile pretreatment of copper catalyst substrates using an ammonium persulfate solution. RSC Advances, 2019, 9(36): 20871-20878.

[30] LI F, LU L Y, GAO D, et al. Rapid synthesis of three-dimensional sulfur-doped porous graphene via solid-state microwave irradiation for protein removal in plasma sample pretreatment. Talanta, 2018, 185: $528-536$.

\title{
铜基底预处理对 CVD 法生长石墨烯薄膜的影响
}

\author{
孙付通 ${ }^{1,2}$, 冯爱虎 ${ }^{2}$, 陈兵兵 ${ }^{2}$, 于 云 ${ }^{2}$, 杨 红 $^{1}$
}

(1. 上海师范大学 化学与材料科学学院, 上海 200234; 2. 中国科学院 上海硅酸盐研究所, 中国科学院特种无机 涂层重点实验室, 上海 201899)

摘 要: 化学气相沉积法是制备大尺寸、高质量石墨烯的有效方法, 其中金属催化剂的性能直接关系到所制备的石 墨烯材料的品质，因此需对金属催化剂进行表面预处理。本文研究了不同的预处理工艺对常用的铜基底催化剂表面 状态的影响, 提出了针化膏酸洗和电化学抛光协同处理的有效方法, 并对电化学抛光工艺参数(抛光电压、时间)以 及铜基底退火工艺(退火温度、时间)等进行了系统研究。研究表明: 电化学抛光电压过高、抛光时间过长容易导致 过度抛光, 合适的抛光电压和抛光时间分别为 $8 \mathrm{~V}$ 和 $8 \mathrm{~min}$ 。退火温度和时间对铜催化剂表面晶粒形态影响较大, 经 $1000{ }^{\circ} \mathrm{C}$ 退火处理 $30 \mathrm{~min}$ 后, 铜箔表面晶粒尺寸更大, 分布更均匀。此外, 对 CVD 法生长制备的石墨烯样品进行表 征, 电镜图片和拉曼光谱显示, 获得的石墨烯薄膜的层数较少, 且结构缺陷较少。

关 键 词: 铜基底; 预处理; 化学气相沉积法; 石墨烯

中图分类号: TQ174 文献标识码: A 